\title{
Effectiveness of Wikis for Team Projects in Education
}

\author{
Elizabeth Koh \\ Department of Information Systems \\ National University of Singapore \\ ekoh@comp.nus.edu.sg \\ John Lim \\ Department of Information Systems \\ National University of Singapore \\ jlim@nus.edu.sg
}

\begin{abstract}
From its humble beginnings, wikis have evolved in both business organizations and educational institutions, catering to, among other uses, training and education. The current work examines wikis in the context of collaborative learning project teams and aims to address a visible gap in research. Much previous work is but prescriptive guidelines and self-reflections. While attempts exist in dealing with some assessments of wiki-related teams, these works chiefly use shortterm teams and place their emphasis on merely outcomes. We advocate examination of mature teams as well as the interaction processes that happen while teams operate. The current study pays attention to four inputs highlighted as salient previously: learners' prior wiki experience, instructor' s support, age and gender. It offers in-depth understanding of wiki effectiveness in collaborative learning environments, operationalized using project teams. A theoretical model is developed using the lens of the functional perspective, proposing wikis to positively affect learning outcomes of academic achievement, self-reported learning, process satisfaction, positive social environment and a sense of community, through the processes of task-related and socioemotional activities. The model posits that the inputs will enhance these activities. Tested using two separate wikis (Mediawiki and Confluence) over a protracted period of one semester, our findings show strong support for wiki effectiveness, contributing to research areas including wikis and small groups. With sound basis, the paper puts forth a framework for conceptualizing the notion of levels in segregating wiki systems, permitting derivation of implications for wiki development and instructional use.
\end{abstract}

Keywords: Wiki, Team, Effectiveness, Small group behavior, Learning, Education 


\section{Introduction}

From its beginnings as an information system for programmers to easily share code patterns, wikis have evolved and found myriad uses in organizations (Leuf \& Cunningham 2001; McAfee 2006; Ebersbach et al. 2008). This is especially true in education, where wikis have been deployed in research and writing assignments, group authoring projects, peer review and online/distance education (Hew \& Cheung 2009; Kane \& Fichman 2009). Wikis, basically websites where many authors can edit, are being used as a means to promote deeper learning, enhance collaboration skills and facilitate the knowledge discovery of students (Parker \& Chao 2007; Chen et al. 2005; Mader 2006). More studies have been published regarding wiki use in education. However, these studies have mainly been descriptive with prescriptive guidelines or a self-reflection without rigorous investigation (Hew \& Cheung 2009). Some papers provide theoretical explanations and report technical designs of the wiki. A few studies on wiki effectiveness can be found but are nonetheless limited in terms of some crucial aspects (Ramanau \& Geng 2009). Greater empirical efforts to examine learning outcomes from using the wiki are in want (Forte \& Bruckman 2007). Moreover, previous studies tended to examine short durations which prevented mature groups from using wikis and could have but manifested a novelty effect (Hew \& Cheung 2009). It has been suggested that students' previous experience with wikis could affect the team interaction and learning outcomes (Shih et al. 2006; Hong 2002). Similarly, in online learning, studies have questioned the role of the instructor, who may not be as visible in the wiki (Lund \& Smødal 2006; De Laat et al. 2007). Age and gender could also affect the use of wikis for learning (Ramanau \& Geng 2009). More in-depth research and cleverer measurement methods of wiki effectiveness in collaborative learning environments are needed (Wagner 2004).

While wikis can be used for classroom communities, this research addresses an important emerging area concerning the aspect of teamwork. In this way, the paper draws from and contributes to small group research and socio-psychology research, on top of its primary nature in Information Systems (IS). In addition, the paper will open up the black box between the input and outcome layers, thus allowing the examination of the interaction processes that occur in small group activities. Pioneer research by Bales (1950) showed that a group is in a continual state of dividing its time and work between instrumental (taskrelated) and expressive (socio-emotional) needs. Thus, interacting processes consist of two main types of behavior - task-related and socio-emotional activities. In this regard, learning outcomes examined should relate to the cognitive and social dimensions consisting of the learning performance and sociorelated outcomes of students (Kreijns et al. 2002).

Examining inputs, processes and outputs is the normative approach in IS and small group literatures. Researchers have termed this the functional perspective as group output is viewed as a function of inputs and processes (Wittenbaum et al. 2004). The key question of this study is: does the use of a wiki for team projects affect learning outcomes? Surrounding this theme the paper examines specifically the influence of salient input factors (learners' prior wiki experience, perceived instructor support, age and gender) on task-related and socio-emotional activities which affect the learning outcomes of academic achievement, self-reported learning, process satisfaction, positive social environment and sense of community. This paper also contributes toward understanding the impact of different types of wiki software in education as data was collected from two wikis, one based on Mediawiki software and the other, Confluence software. Theoretical and practical implications from this research will be discussed.

The structure of the paper is as follows. First, the conceptual framework of the research is laid out. The paper will elaborate on the importance of wikis in team projects, the learning outcomes and the interaction process. Research hypotheses will also be proposed followed by the description of the research 
model. Next, the research methodology will be delineated. Data will be analyzed for the two wikis separately followed by an overall discussion. The paper ends with implications and concluding remarks.

\section{Conceptual Framework}

\section{Wikis for Team Projects in Education}

Wikis are basically collections of web pages. Many different wiki software exists but all share the common features of shared editing, tracking functions and page permissions. Wikis are starting to become common in educational landscapes due to the technology being easily available (Ebersbach et al. 2008). Various free or low-cost wiki software can be adopted by learners or educators such as hosted solutions (e.g. Wetpaint, PBWorks, and Confluence) or open-sourced solutions (e.g. Mediawiki, PMWiki, and Tikiwiki). Elgort (2007) describes wikis used in education as "academic or learning wikis, incorporating elements of social software, a group project tool and an academic study tool" (p.236). See Parker and Chao (2007) and Ebersbach et al. (2008) for more details about wikis.

Wikis have been used in many ways such as the construction of a case library, wiki Micropedias, FAQ wikis, crowdsourced textbooks, problem solving wikis, and project spaces (Kane \& Fichman 2009). For instance, one of the forerunners of wiki systems for education is the CoWeb implemented at the Georgia Institute of Technology (Guzdial et al. 2001). The CoWeb usage can be divided into these three areas: distribution of information, creation of collaborative artifacts, and discussion and review.

Another example is the use of wikis as textbooks. Ravid and colleagues used a wiki based on Mediawiki software to develop a Hebrew textbook on Information Systems (Ravid et al. 2008). This wiki was seeded with an older version of a textbook and students were responsible for updating content to it. Schacht (Schacht 2006), an English professor, in a Collaborative Writing Project instructed students to write individual essays on their interpretations of literary concepts and share it with the rest of the class on the wiki. In addition, a "Dictionary of Literary Terms" was also compiled by his students.

Although there are a myriad of uses, wikis are heralded for its ability to allow group authorship in which team members use a shared workspace to discuss and create a co-written document in the context of learning (Parker \& Chao 2007). Socio-constructivism suggests that people learn best when they share, cooperate, reflect and negotiate (Vygotsky 1978). Also known as collaborative learning, the theory has been a guiding principle in many educational activities such as team projects.

\section{Wikis and Learning Outcomes}

Some studies have examined the relationship between wiki use and learning outcomes. Nicol et al. (2005) examined a collaborative activity that involved students co-creation engineering designs using a wiki based on the TikiWiki software. The wiki allowed teams to communicate and share resources. Students reported being satisfied with the wiki experience. Tutors also remarked that the wiki helped to improve the quality of projects compared to earlier batches of teams (Nicol et al. 2005). In a distance learning course, Minocha and Thomas (2007) highlight how the wiki helped students in collaborative learning by gathering the team's knowledge in one shared workspace rather than dispersed across different communication channels. Although there were difficulties such as usability issues and communication lags, overall students perceived that they learnt from the comments received from group members and other team discussions on the wiki.

Hew and Cheung (2009) observe that wiki research has examined learner outcomes in two areas: learning and affect. In another conceptualization, Kreijns et al. (2002) highlight two slightly different areas: learning performance and social performance. Learning performance consists of the domains cognition and affect, and includes the previous mentioned areas of learning and affect (Bloom 1956; Hew \& Cheung 2009). Social 
performance, also termed socio-related outcome, deals with feeling, being and relationships. It is a measure of the student's ability to interact with other people and to function in groups. Socio-related outcomes emphasize the social environment as a result of interactions on the system (Kreijns et al. 2002). Both learning performance and socio-related outcomes are important outputs of using wikis for team projects in education. Learning performance evaluates the actual learning as well as students' attitude toward the wiki experience while socio-related outcomes assess if through the wiki learners are able to interact socially and build a community.

This paper will examine the learning performance of academic achievement, selfreported learning, and process satisfaction and the socio-related outcomes of a positive social environment and a sense of community (Arbaugh \& Benbunan-Fich 2006; Kreijns et al. 2007; Rovai 2002). Academic achievement refers to the cognitive gain of learners. Self-reported learning is the perceived cognitive knowledge or skills acquired (Alavi 1994). Process satisfaction is the degree to which the learner feels a positive association with the group-solving process (Green \& Taber 1980). Positive social environment is the overall social climate of the team in terms of work relationships, trust, respect and belonging (Kreijns et al. 2007). Sense of community refers to the feeling of connectedness among the learners (Rovai 2002).

\section{The Interaction Process of Teams us- ing Wikis}

An understanding of the interacting processes in wikis is in want. However, very little research has examined the interaction processes in teams using wikis. To open up the black box, the research leans on the wellestablished group interaction process analysis by Bales (1950). According to this perspective, any small group fundamentally occupies itself with two types of activities - taskrelated and socio-emotional activities. In a seminal study, Bales found that groups continually divide their time between instrumental (task-related) and expressive (socio- emotional) needs. The research theorized an equilibrium model in which groups seek to maintain a balance of instrumental and expressive acts through progressive stages. Successful group outcomes then depend on how groups are able to solve the task and maintain member satisfaction.

Some studies have expanded the two processes into three processes dividing socioemotional activities into relating to others and representing the group e.g. the Cognitive three-process model of group interaction (Whitworth et al. 2000). Similarly the "Time, Interaction, and Performance" model (McGrath 1991) regards group behavior as consisting of production, well-being, and member-support processes. While differing ways of dissection have been attempted, none deviates from the fundamental tasksocial perspective.

Moreover, in traditional IS and education research, the social aspect of interaction has been frequently overlooked. The focus is only on task-related activities. For instance, (Bonk et al. 1998) referred to socio-related activity as "social acknowledgments" in students" postings. Moreover, they regarded these interactions as unproductive. A whole stream of computer-mediated communication (CMC) research has also just focused on taskoriented communications while ignoring the socio-oriented activities (Liu 2002).

Geer (2006) highlights the importance of social interactions in her "framework of technology-mediated interaction for education" where social interaction forms the base of a pyramid for different types of interactive pedagogies. The research stresses that socioemotional activity is a crucial foundation for interaction over CMC especially for group collaboration. In an empirical work, Arbaugh and Benbunan-Fich (2006) comment that the social dimension of learning is "essential for the success of online courses, where the sense of the classroom otherwise may be lost" (p.445). In the same vein, this research regards task-related and socio-emotional activities as important for learning outcomes. Viewing one type of interaction alone is insufficient 
to fully investigate the impact of wiki use over time.

In the current context, task-related activity refers to behavior that is focused on work. It includes actions such as asking for information and providing information on the task. Socio-emotional activity refers to behavior that is focused on feelings and the self. It includes expressing affection and sharing personal information.

\section{Task-related activity}

Task-related activity could affect the learning performance and socio-related outcomes of students. Higher task-related activity such as information sharing would imply that students are thinking and analyzing the problem which is part of the learning process. When students verbalize and write out their thoughts, they are able to reflect about the task at hand and also generate new ideas. Textual communication between students also allows them to clarify thoughts and develop a frame of thinking. Cress and Kimmerle (2008) explain that wikis allow learners to externalize and internalize knowledge through information exchange. For instance, as learners author a wiki page, they introduce information which reflects their own knowledge. The mental effort required in the contribution of information can also extend the learner's own knowledge as externalization requires mental processing and clarification (Cress \& Kimmerle 2008). Several studies have reported that students perceived that the wiki facilitated learning of course concepts (Forte \& Bruckman 2007; Minocha \& Thomas 2007). Mindel and Verma (2006) found that the wiki enables collective knowledge in a course and a chronological history of the evolution of the knowledge base. Students perceived the value in using wikis such as encouraging dialogue while writing, which improves the quality of their output. Rick and Guzdial (2006) report on a field study in an English composition class where one section was randomly selected to use a wiki, and the other, an electronic forum to comment on text readings. Students using the wiki had higher academic grades compared to the forum. In addition, two independent raters found that students in the wiki section did significantly better in terms of critical vocabulary and essay organization in their individual essays (Rick \& Guzdial 2006). The research thus suggests that task-related activities on a wiki enable learners to gain higher academic achievement and perceive greater learning.

H1a: Higher task-related activities will be associated with higher academic achievement.

H1b: Higher task-related activities will be associated with higher self-reported learning.

Moreover, increasing task-related activity could also enhance satisfaction (Chou \& Min 2009; Ras et al. 2007). Ras et al. (2007) found that students had positive attitudes toward the wiki as they used it to share information. Students responded that the system saved them effort in experience management, requirements, design, quality assurance and project management in the Computer Science course. However, the study lacked direct measures to assess reflective learning and the evaluation was rather heuristic. Still, the empirical study contained objective (wiki statistics) and subjective measures (through a questionnaire).

H1c: Higher task-related activities will be associated with higher process satisfaction.

In addition, task-related activity as students exchange information for team projects can enhance the social environment and the sense of community (Fuchs-Kittowski \& Köhler 2005). As learners make suggestions and ask for information from their teammates, they put effort into the task, and a positive learning climate is fostered. Students also build a sense of cohesion with their teammates as they share information on a collective task. Chou and Min (2009) found that breadth and depth of information sharing significantly influences the learning climate. This provides support for the following hypotheses on socio-related outcomes: 
H1d: Higher task-related activities will be associated with higher positive social environment.

H1e: Higher task-related activities will be associated with an increased sense of community.

\section{Socio-emotional activity}

Socio-emotional activity can be positive or negative in nature. Research has reported several studies in which learners were fearful of participating in wikis for reasons such as not wanting other members to edit their work (Minocha \& Thomas 2007) or unwilling to display incomplete drafts of their articles (Carr et al. 2007). However, positive socio-emotional activity such as expressing friendliness, positive affection, and encouragement in the wiki enables members to develop trust (Flammia et al. 2010), and common ground to communicate more effectively, which will affect the learning performance (Chudoba et al. 2005). In this regard, the paper will focus on the positive side of socio-emotional activity which can facilitate learning outcomes.

Socio-emotional activity is important for the development of higher learning outcomes (Barab \& Duffy 2000). Socio-emotional activity such as showing solidarity, care and concern for others enables students to work together cohesively in a group, thereby producing better results (Kreijns et al. 2007). Carr et al. (2007) found that encouragement and informal conversation of students on the wiki improved the learning process and student perceptions. Similarly, Benbunan-Fich and Hiltz (2003) found that socio-emotional activity helped to increase learner's motivation, which made them work harder and learn more (Benbunan-Fich et al. 2003). In an empirical study of face-to-face and computermediated teams, Tutty and Klein (2008) found that CMC groups had higher academic grades than face-to-face teams. Incidentally, groups using $\mathrm{CMC}$ had more socio-emotional communication than face-to-face groups. The research suggests that socio-emotional activity motivated students' to do well in the task which facilitated their academic performance (Tutty \& Klein 2008). In the same way, the following should apply to wiki-based team collaboration. This suggests the following hypotheses:

H2a: Higher socio-emotional activities will be associated with higher academic achievement.

H2b: Higher socio-emotional activities will be associated with higher self-reported learning.

Socio-emotional activity can also improve learner satisfaction. Flammia et al. (2010) qualitatively examined seven virtual teams which used several technologies including a wiki for a Technical Communication project. The study identified 3 teams with strong socio-emotional activities including providing humor, sharing of personal details, and encouragement. The study found that these teams participated actively, had a strong sense of ownership to the project, and were highly satisfied with the experience. For teams that did not engage in much socioemotional activity, they regretted the lack of social interaction, and were less satisfied with the experience. This suggests that

H2c: Higher socio-emotional activities will be associated with higher process satisfaction.

Socio-emotional activity also allows members to establish trust and perceive a safe and welcoming team environment (Kreijns et al. 2007). Demonstrating friendship, courtesy, and expressing positive affect will engender feelings of community and a sense of belonging in the team. For instance, research has shown that more socio-emotional communication provides members with better social relationships in the team (Robey et al. 2000). The resulting hypotheses for socio-related outcomes are:

H2d: Higher socio-emotional activities will be associated with higher positive social environment.

H2e: Higher socio-emotional activities will be associated with an increased sense of community. 


\section{Influencing Factors}

\section{Wiki Experience}

Previous wiki experience could affect subsequent interaction processes and outcomes. Past literature has suggested that previous computer experience is a differentiating factor with students who use information and communication technology (ICT) to learn (Yan 2006; Lou et al. 2001; Shih et al. 2006). Students who had more computer experience were more satisfied with their web-based course (Hong 2002) while students who lacked computer experience experienced more stress and anxiety with IT (Lou et al. 2001).

Other research shows that previous computer experience does affect subsequent computer performance (Yan 2006). A longitudinal study by Yan (2006) examined four types of previous experiences - computer network experience, statistical program experience, email experience, years of computer use. The study found that students' who had previous experience with using computer network systems performed better initially in the project. The author explains that this due to the transfer of specific skills which were relevant to completing the project. In the same way, previous experience with a wiki, which includes students' knowledge of how to navigate the wiki, how to edit text and discuss etc., would be instrumental in enabling task and socioemotional activity in the wiki. The following hypotheses are proffered:

H3a: Previous experience of using wikis will predict task-related activity such that more experience will result in higher task-related activity.

H3b: Previous experience of using wikis will predict socio-emotional activity such that more experience will result in more positive socio-emotional activity.

\section{The Role of the Instructor}

The responsibility of the instructor is increasingly being studied in online contexts (De Laat et al. 2007; Lund \& Smødal 2006). This is more so in the context of a wiki where typi- cally the instructor and the student seem to have equal use of the wiki. Lund and Smordal (2006) investigated the instructor's presence in a wiki. They find that wikis do not provide an online space for the instructor as the instructor has the same amount of user rights as the student such as create, edit, move and rename pages and upload files. They are not administrators who can protect pages, delete pages and ban users. This is unlike learning management systems which grants the teacher more access rights and the ability to create and delete pages. Moreover, the instructor's space on the wiki is virtually the same as the student's space. This makes the role of the instructor more ambiguous.

Nevertheless, there is evidence for the importance of instructor support. Instructor support is beneficial in order to scaffold the learning ability of students so that learner can solve problems or accomplish tasks that would otherwise be out of reach. Garrison and colleagues (2000) add that although social and task-related interactions are necessary in online environments, they are not sufficient to ensure higher learning outcomes; rather, instructor support is required "to design and integrate the cognitive and social elements of a community of inquiry for educational purposes" (p. 92). Research has also demonstrated the importance of indirect instructor support which could be in the form of instructional design and structure developed by educators and educational technologists (Kanuka et al. 2007; Elgort 2008; Mindel \& Verma 2006).

Cubric (2007) reports that students were unwilling to engage in wiki learning activities possibly because of unfamiliarity with collaborative learning and low interest. Instructors had to stimulate the student's interaction with the wiki. The research concludes that the student's interaction with the wiki and other learners depended on the frequency and quality of the instructor interactions, and also the weight of the assignment (Cubric 2007). Thus, the paper believes that instructor support is positively related to task-related and socio-emotional activity. 
H4a: Instructor support will predict taskrelated activity such that more instructor support will result in higher taskrelated activity.

H4b: Instructor support will predict socioemotional activity such that more instructor support will result in more positive socio-emotional activity.

\section{Age}

Some studies have reported that age has no impact on interaction processes and outcomes (Hong 2002; Karuppan 2001). Nevertheless, preliminary research has highlighted that the age of learners could affect certain processes and outcomes. For instance, Ramanau and Geng (2009) performed a University-wide survey and found that the age of learners affected wiki use. Students aged 20 to 25 years were more likely to use wikis than students aged 17 to 19 years of age or students aged 26 years of age and older.

As for task-related and socio-emotional activities, research on learning approaches and developmental theories provide some evidence for age-related differences. Past research has shown that older learners tend to adopt a deep approach to learning rather than a surface approach (Gow \& Kember 1990; Richardson 1994). The deep approach to learning involves the critical analysis of ideas and associating with known concepts. This suggests elaboration, debate and negotiation, all highly intensive task-related activities. On the other hand, the surface approach to learning is related to the acquiescence of information and memorization of unlinked facts. It implies that information will be exchanged without further examination of the details i.e. lower task-related activities will occur. This suggests that older learners will tend to have higher task-related activity e.g. discussing and sharing information as compared to younger learners.

According to developmental theories, older individuals tend to be more self-motivated, disciplined and also have wider life experiences than younger individuals (Harter 1999). This suggests that older learners may want to steer the project forward by promoting affect and support to the team. The wealthier experiences of older learners may also equip them with the strategies to manage group learning in teams such as showing encouragement to team members. In so doing, socio-related activity will be greater for older learners as compared to younger learners. Past studies have provided evidence that age does affect interaction and learning outcomes i.e. older learners performed better than young learners (Dille \& Mezack 1991; Swan et al. 2000). The paper suggests that:

H5a: Age will predict task-related activity such that older learners will result in higher task-related activity.

H5b: Age will predict socio-emotional activity such that older learners will result in more positive socio-emotional activity.

\section{Gender}

Gender may also affect the interaction process in wikis. Past research has suggested several views for gender differences including the task and relationship orientation (Hahn \& Litwin 1995) and gender-role socialization and stereotypes (Kray et al. 2002). The task and relationship orientation postulates that men are task-oriented and value selfsufficiency and status, while women are relationship-oriented and value their own and others' needs. In other words, males tend to value status more while females value connections more. The gender-role socialization and stereotypes perspective posits that gender roles are learnt from young. Societal norms have deemed the traditional gender role namely that men are aggressive and competitive while females are nurturing and cooperative. Socialization through living in the community reinforces the stereotype.

In CMC, gender difference has been found for communication styles (Lind 1999; Guiller \& Durndell 2007). Males tend to come across authoritative and argumentative as compared to females who seem to be more encouraging and nurturing (Thomson 2006). In online discussion groups, Guiller \& Durndell (2007) found that males were more task-oriented 
and focused on sharing information in terms of authoritative language as compared to females. In contrast, females wanted to express support and their feelings and engage in more positive socio-emotional activity than men. Similarly, the research posits that in wiki-based groups, a form of CMC, males would have higher task-related activity as compared to females while females would have higher socio-emotional activity as compared to men.

H6a: Gender will predict task-related activity such that male learners will have higher task-related activity as compared to female learners.

H6b: Gender will predict socio-emotional activity such that female learners will have more positive socio-emotional activity as compared to male learners.

\section{Research Model}

Informed by the literature discussed earlier, a theoretical model in the lens of the functional perspective is developed. This comprises the inputs of wiki experience, instructor presence, age and gender, the instrumental processes of task-related and socio-emotional activity and finally the outputs of learning performance and socio-related outcomes categories. The model is depicted in Figure 1. All the relationships are in the positive direction.

\section{Research Methodology}

\section{Research Context and Project Task}

A wiki was introduced in a module that taught societal issues related to ICT for a team project. This project required students of 3 to 6 members to co-author a report on a particular aspect of ICT on the wiki. The pedagogical goal of this project was for students to gain in-depth knowledge of ICT issues. It was hoped that the students would be able to learn to use wiki systems to collaborate more easily and create their report. This project was carried out twice over two semesters under the same instructor and tutor. The project was a requirement for all students and worth 50 per cent of their course grade. The goal and requirements of the project was the same in both semesters, but the wiki software adopted was different. For both wikis, students used it for about 4 months for their team project. Students created a home page on the hosted wiki for their group project. The website subsequently expanded as students created and linked to other pages on the wiki. As this course was not an online course, students could meet team members face-to-face. However, students were required to submit and display their project on the wiki, which ensured that the group would make use of the wiki. In the first semester, the teaching staff provided project instruction and technical help to the students. However, the teaching staff realized that students tended to use the wiki to upload the final report, and did not use the features of the wiki to collaborate online. During the next semester, the staff provided a training session to encourage students to use the wiki to collaborate online in addition to project details and technical help.

\section{Choice of Wiki Software}

In the first semester, the wiki software, Mediawiki was utilized. Mediawiki is the software used by Wikipedia, a popular online encyclopedia and its interface is familiar to most students. The instructor selected this software as it was thought that student's familiarity with Wikipedia's interface would help increase the usability of the wiki. Mediawiki is also available freely and open source. A tutor helped to set-up the software in a server. In the second semester, the wiki software, Confluence was used. The reason for the change is that the University recently acquired the Confluence software and made it available for all students and the instructors wanted to try out this new system.

They are slight differences in the features of the wiki software. Mediawiki does not have WYSIWYG editing ${ }^{1}$ and students can find learning wiki mark-up language difficult to use. Moreover, comments are written in a freeflow discussion page. Students can also edit individual sections. On the other hand, Confluence is a hosted wiki solution by Atlassian. Confluence has WYSIWYG editing, and its comments are in a threaded form, making it 


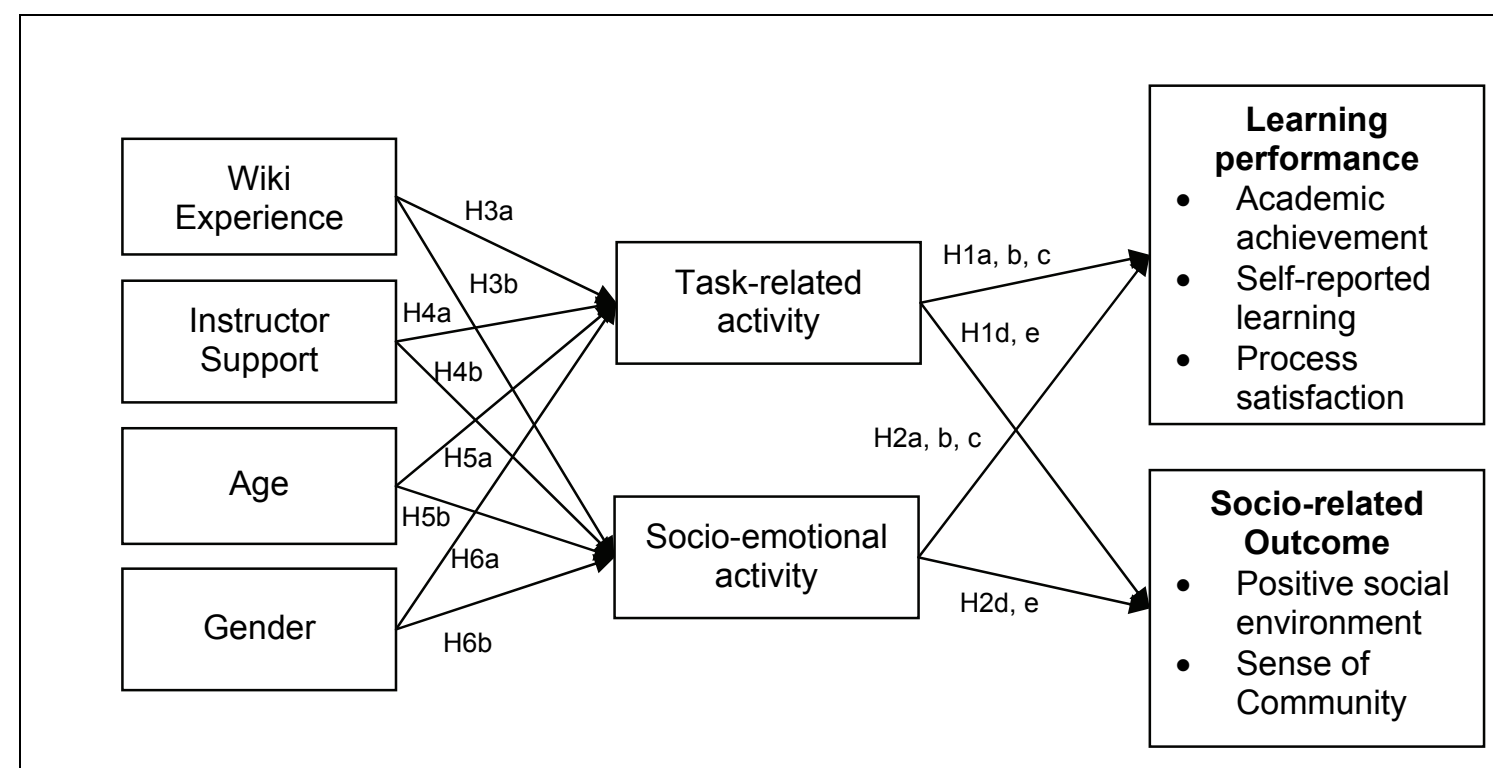

Figure 1 - Research Model

easier to follow discussions. Students can indicate if they want changes to the wiki to be emailed to them, and they could also upload a user profile photo. Screenshots of the two software are shown in Figures 2 and 3. Feature-by-feature comparison details can be viewed at http://www.wikimatrix.org/compare/ Confluence+MediaWiki.

\section{Survey Instrument}

The survey methodology was chosen to investigate students' perceptions of wiki effectiveness. The survey method is useful for examining relationships between attitudes and beliefs. Survey items were sourced from past literature. The items comprised of one-item measures for the demographics of age, gender and wiki experience (WExp). Multiple items were utilized for the measures instructor support (InstSup), task-related activity (TaskRA), socio-emotional activity (SocioEA), self-reported learning (SRLearn), process satisfaction (PSat), positive social environment (PSocEnv) and sense of community (SComm). A pre-test was conducted with 5 faculty members for content validity. The sorting resulted in the deletion of ambiguous items. The survey items were measured using a scale of 1 to 7 points where 7 is the highest value. The instrument is shown in Table 1.
As for academic achievement (AcadA), this was measured objectively with the actual grade of the project. AcadA was assessed on the criteria topic coverage, correctness, connectivity, language, and student's attainment of in-depth ICT knowledge. The same tutor marked the projects from both wikis. Average AcadA was 33.7 for the first semester (std dev 3.60) and 33.6 for the second (std dev 4.81).

\section{Survey Responses}

The survey was conducted after students submitted their project. Survey participation was voluntarily and additional participation marks were awarded to students if they participated. There were 63 students in the first course and 45 students responded to the survey which represented all the 15 groups. For the second course, there were 104 students and 86 respondents representing all the 21 groups. The response rate was $71.4 \%$ and $82.7 \%$ for the two surveys respectively. Each course consisted of new students; there were no students who repeated the course. Consistent with the approach of other studies which examine the individual's perceptions of the group (Jarvenpaa et al. 2004; Hoyle \& Crawford 1994), data was analyzed at the individual level. The average age of students was 21.71 and 20.43 for the first and second 
survey respectively. There were $77.8 \%$ males (22.2\% females) in the first survey and $54.7 \%$ (45.3\% females) in the second. Age and gender statistics were representative of the course i.e. relatively young students as this was a first-year module and higher number of males which is typical in a computing course. Moreover, this was a strata sample of the freshman population of the University. Further break-downs and other demographics are reported in Table 2. For instance, WExp for both wikis was low as $33.3 \%$ and $55.8 \%$ of students respectively for survey 1 and 2 were using it for the first time. The mean results for the items are also shown in Table 1.

\section{Table 1 - List of Constructs and Measures}

\begin{tabular}{|c|c|c|c|c|}
\hline Constructs & Measures & $\begin{array}{c}\text { Mean } \\
\text { (Wiki } \\
\text { 1) }\end{array}$ & $\begin{array}{c}\text { Mean } \\
\text { (Wiki } \\
2 \text { ) } \\
\end{array}$ & Sources \\
\hline \multicolumn{5}{|c|}{ Instructor Support (InstSup) } \\
\hline InstSup1 & I was aware of the instructor's online presence & 3.51 & 3.88 & \multirow{5}{*}{$\begin{array}{c}\text { Garrison et al. } \\
\text { (2000); Kanuka } \\
\text { et al. (2007) }\end{array}$} \\
\hline InstSup2 & The instructor was available to me & 3.93 & 4.23 & \\
\hline InstSup3 & The instructor was available to my group members & 4.02 & 4.36 & \\
\hline InstSup4 & The instructor facilitated my group's activity in the online medium & 3.58 & 3.76 & \\
\hline InstSup5 & Overall, I had a great deal of interaction with my instructor & 3.42 & 3.63 & \\
\hline \multicolumn{5}{|c|}{ Task-related Activity (TaskRA) ${ }^{2}$} \\
\hline TaskRA1 & I made suggestions about the task & 5.20 & 5.73 & \multirow{3}{*}{$\begin{array}{l}\text { Bales (1950); } \\
\text { Green \& Taber } \\
(1980)\end{array}$} \\
\hline TaskRA2 & I gave information about the problem & 5.38 & 5.56 & \\
\hline TaskRA3 & I asked for information from others & 4.98 & 5.38 & \\
\hline \multicolumn{5}{|c|}{ Socio-emotional Activity (SocioEA) ${ }^{2}$} \\
\hline SocioEA1 & Others expressed a positive opinion about your behavior & 5.13 & 5.12 & \multirow{3}{*}{$\begin{array}{c}\text { Bales (1950); } \\
\text { Green \& Taber } \\
(1980)\end{array}$} \\
\hline SocioEA2 & I was unfriendly (reversed) & 5.69 & 5.95 & \\
\hline SocioEA3 & I was frustrated (reversed) & 5.93 & 6.07 & \\
\hline \multicolumn{5}{|c|}{ Self-reported learning (SRLearn) } \\
\hline SRLearn1 & I was more confident in expressing ideas & 4.87 & 5.12 & \multirow{4}{*}{ Alavi (1994) } \\
\hline SRLearn2 & I learned to interrelate important topics and ideas & 5.09 & 5.20 & \\
\hline SRLearn3 & I increased in understanding of basic concepts & 4.91 & 5.27 & \\
\hline fSRLearn4 & I learned to identify central issues & 5.04 & 5.14 & \\
\hline \multicolumn{5}{|c|}{ Process Satisfaction (PSat) } \\
\hline PSat1 & I would describe my team's problem-solving process as fair & 5.11 & 5.33 & \multirow{3}{*}{$\begin{array}{c}\text { Green \& Taber } \\
(1980)\end{array}$} \\
\hline PSat2 & $\begin{array}{l}\text { I would describe my team's problem-solving process as under- } \\
\text { standable }\end{array}$ & 5.00 & 5.30 & \\
\hline PSat3 & I would describe my team's problem-solving process as satisfying & 5.18 & 5.33 & \\
\hline \multicolumn{5}{|c|}{ Positive Social Environment (PSocEnv) } \\
\hline PSocEnv1 & $\begin{array}{l}\text { Teammates felt free to criticize ideas, statements, and/or opinions } \\
\text { of others }\end{array}$ & 5.16 & 5.57 & \multirow{9}{*}{$\begin{array}{l}\text { Kreijns et al. } \\
\quad(2007)\end{array}$} \\
\hline PSocEnv2 & Teammates ensured that we kept in touch with each other & 5.00 & 5.47 & \\
\hline PSocEnv3 & We worked hard on the team assignment & 5.13 & 5.76 & \\
\hline PSocEnv4 & I maintained contact with all other teammates & 4.98 & 5.58 & \\
\hline PSocEnv5 & Teammates gave personal information on themselves & 4.53 & 5.22 & \\
\hline PSocEnv6 & $\begin{array}{l}\text { The team conducted open and lively conversations and/or discus- } \\
\text { sions }\end{array}$ & 4.89 & 5.45 & \\
\hline PSocEnv7 & Teammates took the initiative to get in touch with others & 4.91 & 5.40 & \\
\hline PSocEnv8 & Teammates spontaneously started conversations with others & 4.73 & 5.42 & \\
\hline PSocEnv9 & Teammates asked others how the work was going & 4.80 & 5.48 & \\
\hline \multicolumn{5}{|c|}{ Sense of Community (SComm) } \\
\hline SComm1 & I feel that students in this course care about each other & 3.93 & 4.65 & \multirow{3}{*}{ Rovai (2002) } \\
\hline SComm2 & I feel connected to others in this course & 4.09 & 4.63 & \\
\hline SComm3 & I feel that this course is like a family & 3.60 & 4.17 & \\
\hline
\end{tabular}


Pacific Asia Journal of the Association for Information Systems, Vol. 3, Iss. 3 [2011], Art. 2

Assessing IT-business alignment in service-oriented enterprises / Koh \& Lim

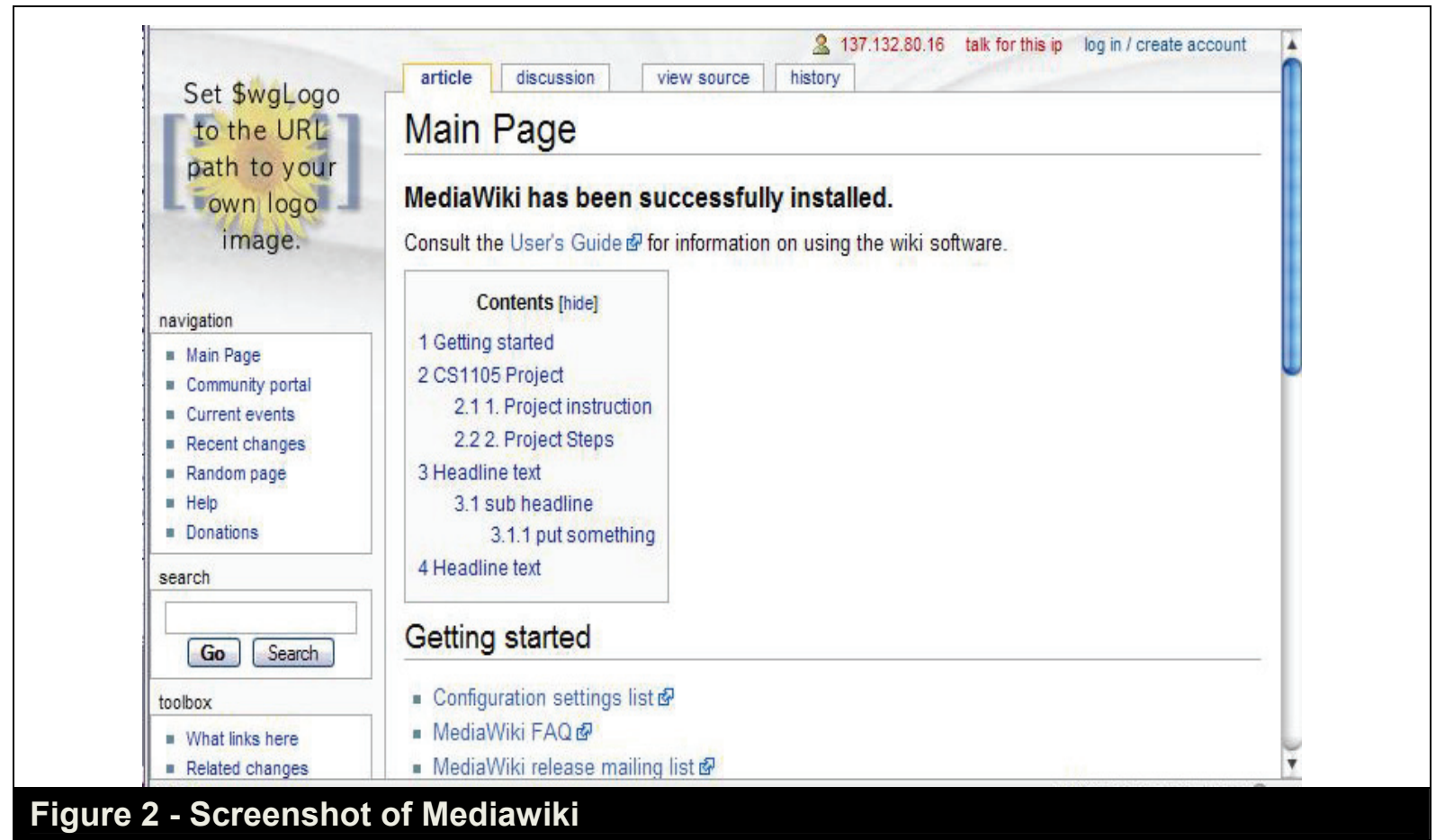

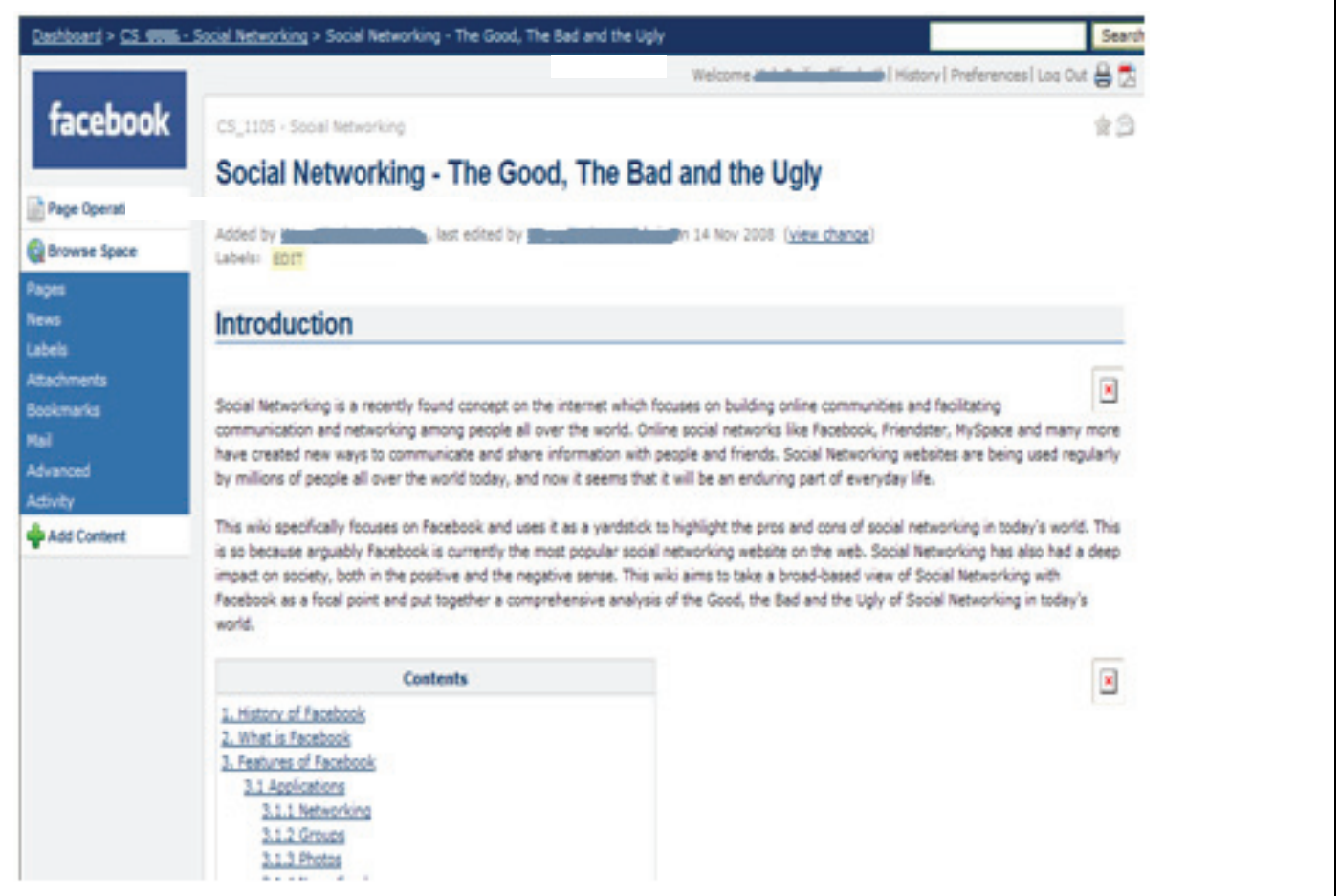

Figure 3 - Screenshot of Confluence

Partial least squares (PLS) analysis was utilized to test the significant relations among the variables. PLS does not have distributional assumptions of data normality and is able to handle small-to medium-sized samples (Chin 1998). The following sections analyze the results and discuss the findings from surveys 1 and 2 respectively. 


\begin{tabular}{|c|c|c|c|c|c|}
\hline \multirow{2}{*}{ Variable } & \multirow{2}{*}{ Category } & \multicolumn{2}{|c|}{ Survey 1 (Mediawiki) } & \multicolumn{2}{|c|}{ Survey 2 (Confluence) } \\
\hline & & Number & Percentage & Number & Percentage \\
\hline $\begin{array}{l}\text { Computer } \\
\text { Experience }\end{array}$ & $\begin{array}{l}\text { Less than } 2 \text { years } \\
2-4 \text { years } \\
4-6 \text { years } \\
6-8 \text { years } \\
\text { More than } 8 \text { years }\end{array}$ & $\begin{array}{l}0 \\
2 \\
3 \\
11 \\
29\end{array}$ & $\begin{array}{l}0 \\
4.4 \\
6.7 \\
24.4 \\
64.4\end{array}$ & $\begin{array}{l}0 \\
0 \\
12 \\
20 \\
54\end{array}$ & $\begin{array}{l}0 \\
0 \\
14.0 \\
23.3 \\
62.8\end{array}$ \\
\hline $\begin{array}{c}\text { Wiki } \\
\text { Experience }\end{array}$ & $\begin{array}{l}\text { Just for this course } \\
\text { Less than } 1 \text { year } \\
1-2 \text { years } \\
2-3 \text { years } \\
\text { More than } 3 \text { years }\end{array}$ & $\begin{array}{l}15 \\
10 \\
7 \\
7 \\
6\end{array}$ & $\begin{array}{l}33.3 \\
22.2 \\
15.6 \\
15.6 \\
13.3\end{array}$ & $\begin{array}{l}48 \\
9 \\
11 \\
13 \\
5\end{array}$ & $\begin{array}{l}55.8 \\
10.5 \\
12.8 \\
15.1 \\
5.8\end{array}$ \\
\hline Age & $\begin{array}{l}17 \\
18 \\
19 \\
20 \\
21 \\
22 \\
23 \\
24 \\
25\end{array}$ & $\begin{array}{l}0 \\
2 \\
3 \\
4 \\
8 \\
13 \\
11 \\
3 \\
1\end{array}$ & $\begin{array}{l}0 \\
4.4 \\
6.7 \\
8.9 \\
17.8 \\
28.9 \\
24.4 \\
6.7 \\
2.2\end{array}$ & $\begin{array}{l}2 \\
7 \\
25 \\
11 \\
19 \\
11 \\
6 \\
2 \\
3\end{array}$ & \begin{tabular}{l|}
2.3 \\
8.1 \\
29.1 \\
12.8 \\
22.1 \\
12.8 \\
7.0 \\
2.3 \\
3.5
\end{tabular} \\
\hline
\end{tabular}

\section{Survey 1 - Mediawiki}

\section{Data Analysis and Results}

Tests to the measurement model revealed adequate internal consistency, convergent and discriminant validity as shown in Table 3 . Internal consistency, which is commonly measured by the Cronbach's alpha test revealed that all constructs met the criterion of 0.700 (Nunnally 1978). Although the Cronbach's alpha of SocioEA was out of the criteria at 0.698 , it was marginally close and past research has used these data for further tests (Fuller et al. 2006). Convergent validity as assessed by composite reliability and average variance extracted were higher than 0.500 (Fornell 1982). To reduce multicollinearity, the variables were centered (Tamhane \& Dunlop 2000). In addition, the constructs had adequate discriminant validity as shown by the square root of average variance extracted exceeding the correlations between the construct and any other construct.

To rule out the effects of common method bias the common method factor approach was applied (Podsakoff et al. 2003). All items were added to a common method factor and run in the PLS model to calculate the vari- ance of the principal constructs and the method (Liang et al. 2007). The research found that the variance of the indicators is 0.712 while the average method-based variance is 0.000001 which represents a ratio of 839796:1. The factor loadings for the method are mostly non-significant. The statistical analysis of the structural model with bootstrapping as well as the model controlled for common method bias is shown in Table 4. For the controlled model, some paths increased slightly in strength, whereas strengths of other paths decreased slightly. However, the pattern of significant relationships did not change. This indicates that the method did not affect the results of the study.

TaskRA could explain $15 \%$ of the variance while SocioEA explained $7 \%$ of the variance from the inputs. Nevertheless there were larger R-squared values for SRLearn $(17 \%)$, PSat $(21 \%)$, PSocEnv (21\%) and SComm $(12 \%)$ except for AcadA (6\%) indicating that the model has good explanatory power. Eleven hypotheses were significant. However, 2 hypotheses were in the direction opposite to the direction predicted. TaskRA was negatively related to SComm, path coefficient = $.366, p<.001$. Males were significantly asso- 
ciated with higher SocioEA, path coefficient $=$ $-0.222, p=0.052$.

\section{Discussion}

It seems that learning outcomes PSat, PSocEnv and SComm can be explained by TaskRA and SocioEA as seen by the relatively high R-squared values. In particular, TaskRA and SocioEA combined affect PSat and PSocEnv the most.

As for the effect of TaskRA on learning performance, this was not evenly supported in the wiki. TaskRA significantly affected AcadA and PSat but not SRLearn. While the results may seem puzzling at first, the lack of significance for SRLearn could be due to students sharing information and coming to quick consensus with each other. As mentioned earlier, students did not use the wiki to discuss information with each other, but rather as a space to upload and deposit what information they had gathered. Students shared this information without going to the extent of expressing personal ideas or identifying the central issue. They did not engage in any task conflict as they were eager to please each other and complete the project smoothly. They could have produced a relatively good project which was well-organized and cohesive which is shown by the significant AcadA. However, students' sharing of information did not contribute to their SRLearn as they went along with sharing superficial information without going in-depth and interrelating the knowledge, or negotiating with other students and conveying their own ideas. In this regard, SRLearn was lowered and not affected by TaskRA. Another possible reason for the lack of significance for SRLearn was that students were already familiar with the topic that had chosen (Ravid et al. 2008). As teams could select their preferred ICT topic, students might have chosen topics which they already had a high amount of knowledge in. Thus, they may not have gained new knowledge or skills as they shared information about the topic. Still, their high level of knowledge about their topic led to them receiving high project grades i.e. AcadA.
A surprising finding was that TaskRA was negatively related to SComm. Too much focus on sharing information led to lower feelings of connectedness among the group. Emphasizing on the task only seems to have alienated team members. The later section will discuss this more.

SocioEA affected learning performance of SRLearn and PSat except for AcadA. A reason for this might be that students who produced more socio-communication naturally felt more positive towards their learning and the process of collaboration. On the other hand students' SocioEA did not translate into good grades as students were more focused on agreeing with other members and not engaging in relational conflict that could have affected the quality of the report. As for the subsequent relationships of the effect of SocioEA on socio-related outcomes, these were all significant in the direction predicted.

Although TaskRA and SocioEA received low $\mathrm{R}$-squared values, several of the relationships between inputs and the interaction process were significant. As highlighted by several researchers (Colton \& Bower 2002; Wildt 1976), low R-squared values do not equate to weak results. Rather, significant relationships among the variables can still exist and should be examined.

From the data, WExp did not affect taskrelated or socio-emotional activity. A possible reason could be the way WExp was measured, it was measured in terms of years of experience rather than students' knowhow of the wiki over the years of using it. Although close to $45 \%$ of the students had used Mediawiki for more than a year, they could have used it at a very basic way in popular platforms like Wikipedia and Wikitravel i.e. browsing through the websites for information. Students might not have had any experience in editing and formatting the wiki which would help them to exchange information easily.

InstSup significantly affected TaskRA as predicted. However, this was not significant for SocioEA. It could be that the instructor during this first semester focused on the task only without encouraging students to socially in- 
teract or manage the team dynamics in the wiki. Nevertheless the sign for SocioEA was in the direction hypothesized. More will be discussed in the overall findings section.

A significant effect was found for age and TaskRA but not for SocioEA. Older learners had more task-related activity probably as a result of deeper learning strategies used. However, both older and younger learners contributed to SocioEA, irrespective of their experience. The lack of age differences could be explained by the generation effect where younger students tend to be more comfortable with technology as compared to older learners (Hills \& Argyle 2003). This may predispose them to share personal information and provide encouragement easily on the wiki.

As for gender, there was no significant effect for gender and TaskRA. However, there was a significant effect between gender and SocioEA opposite to the prediction i.e. males had higher SocioEA than females. Some insight into this finding draws from gender research examining the behavior of gender in teams. Research has shown that the gender composition of team members affect how an individual behaves (Savicki \& Kelley 2000). In mixed-gender groups, females have been shown to behave more task-focused and less socio-emotional than in female-only groups (Flanagin et al. 2002). In this course, there were more males than females, and groups were mostly mixed-gender. This reaction of females in groups explains why there were no significant differences in the relationship between gender and TaskRA. Less SocioEA expressed by females in mixed-gender groups also explains why there was no significant difference in the relationship between gender and SocioEA.

\section{Survey 2 - Confluence}

\section{Data Analysis and Results}

Similar data analysis tests from Survey 1 were performed for the dataset for Survey 2 . Measurement model results reveal general acceptable reliability, convergent validity and discriminant validity (Table 5 ). The variance of the indicators is 0.725 while the average method-based variance is 0.0001 which represents a ratio of 6207:1. The factor loadings for the method are mostly non-significant. The structural model results as well as the model controlled for common method bias are shown in Table 6. There was slightly more fluctuation in the controlled model as compared to the structural model. However, the pattern of the paths did not change. This suggests that the method did not have a large influence on the results of the study.

TaskRA could explain $3 \%$ of the variance while SocioEA could explain $8 \%$ of the variance from the inputs. The R-squared values for AcadA was $3 \%$, SRLearn $27 \%$, PSat $16 \%$, PSocEnv $25 \%$ and SComm $9 \%$. Nine of the 18 paths were significant. However, one hypothesis was supported in the opposite direction. SocioEA negatively affected AcadA, path coefficient $=-.196, p=.029$.

\section{Discussion}

For learning performance, TaskRA affected SRLearn only and not AcadA and PSat. In this survey, the non-significant findings for AcadA and PSat could be because information overload occurred. Students contributed too much task information which was redundant and overlapping leading to displeasure in the work process. Moreover, this information while helping them to understand the issues and learn, was not organized and integrated well into the project which may have led to the lower AcadA.

It was interesting to find that TaskRA significantly influenced PSocEnv but not SComm. A possible reason is that providing information about the project led to group members feeling that there was a positive team climate and the team could work well together. However, this information exchange was not selfrevealing and it was difficult to help group members to get to know each other better.

On the other hand, SocioEA significantly affected all learning outcomes. However, the relationship between SocioEA and AcadA was significant in the opposite direction. Higher SocioEA resulted in lower AcadA. A possible reason for this is that while SocioEA 


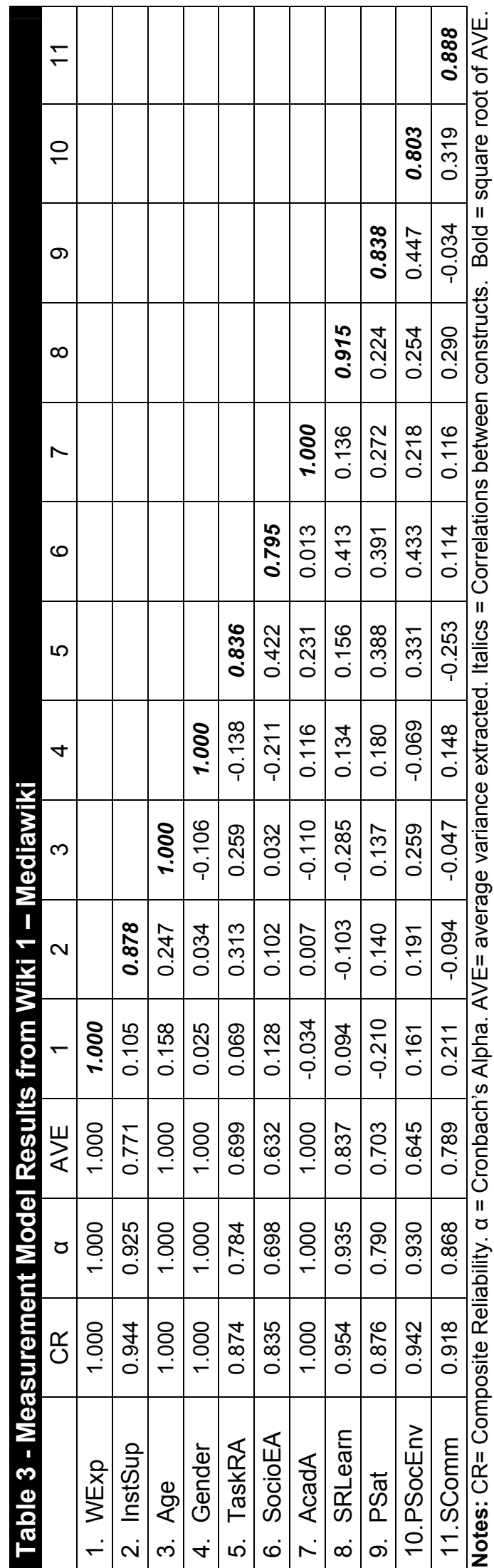

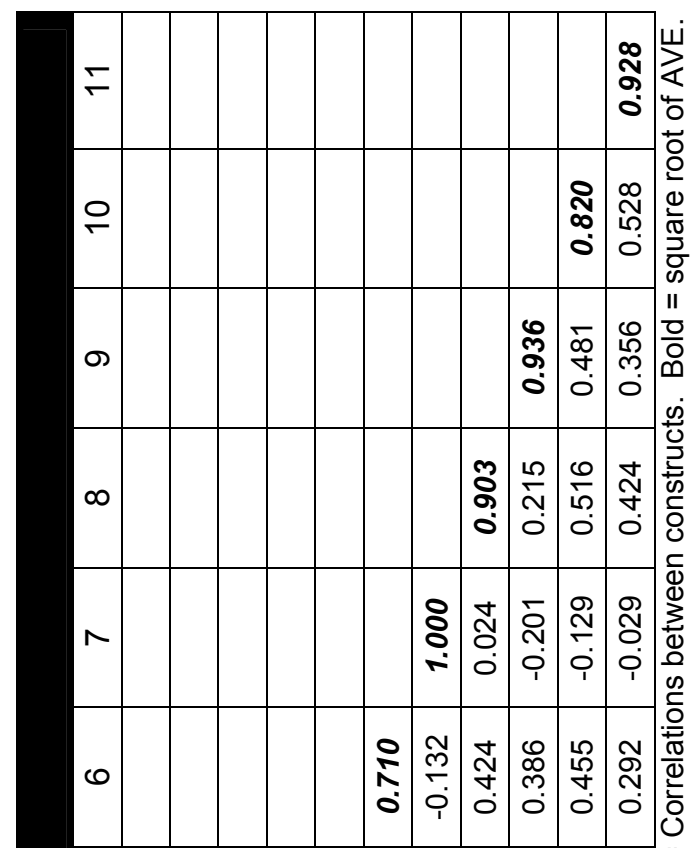

10

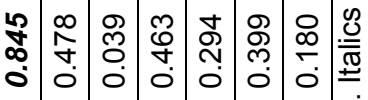

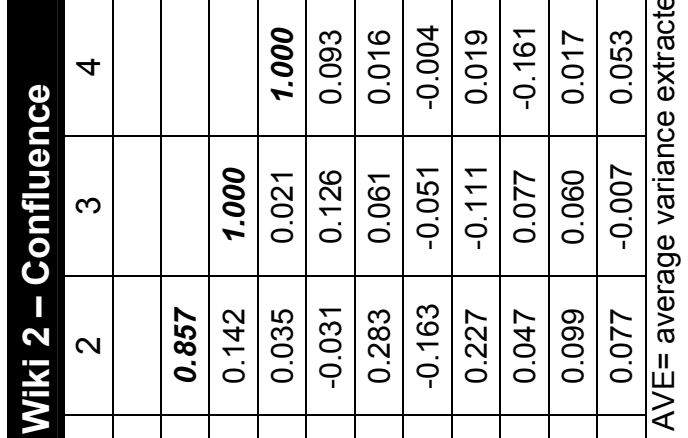

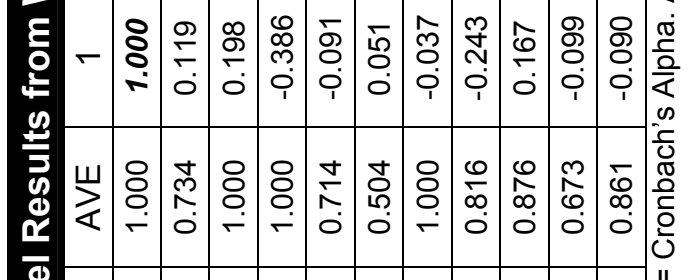

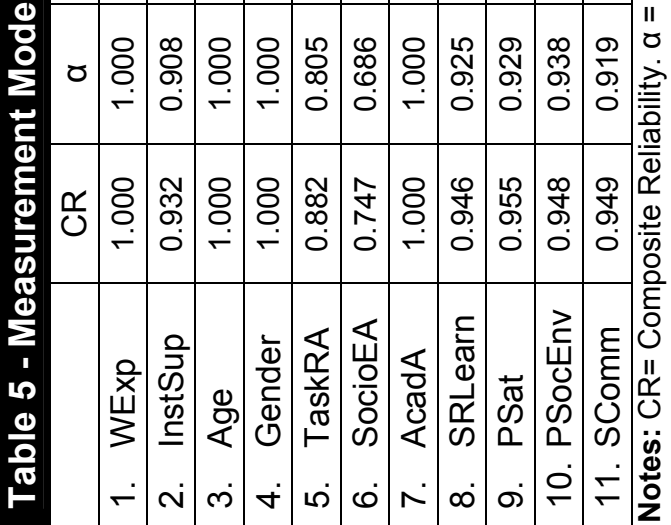




\begin{tabular}{|c|c|c|c|c|c|}
\hline \multirow{2}{*}{\multicolumn{2}{|c|}{ Structural relation }} & \multicolumn{2}{|c|}{ Survey 1 Model } & \multicolumn{2}{|c|}{$\begin{array}{l}\text { Controlling for Common } \\
\text { Method Bias }\end{array}$} \\
\hline & & Path Coeff & t-Value & Path Coeff & t-Value \\
\hline $\mathrm{H} 1 \mathrm{a}$ & TaskRA -> AcadA & $0.274^{* *}$ & 3.432 & $0.270^{* *}$ & 3.328 \\
\hline $\mathrm{H} 1 \mathrm{~b}$ & TaskRA ->SRLearn & -0.022 & 0.121 & -0.014 & 0.089 \\
\hline $\mathrm{H} 1 \mathrm{c}$ & TaskRA -> PSat & $0.271^{* *}$ & 3.199 & $0.291^{* *}$ & 3.665 \\
\hline $\mathrm{H} 1 \mathrm{~d}$ & TaskRA -> PSocEnv & $0.181^{*}$ & 2.143 & $0.168^{*}$ & 2.041 \\
\hline $\mathrm{H} 1 \mathrm{e}$ & TaskRA -> SComm & $-0.366^{* * *}$ & 3.712 & $-0.362^{\star \star *}$ & 4.235 \\
\hline $\mathrm{H} 2 \mathrm{a}$ & SocioEA -> AcadA & -0.103 & 1.173 & -0.100 & 1.258 \\
\hline $\mathrm{H} 2 \mathrm{~b}$ & SocioEA -> SRLearn & $0.422^{\star \star \star}$ & 4.777 & $0.414^{* \star *}$ & 5.709 \\
\hline $\mathrm{H} 2 \mathrm{c}$ & SocioEA -> PSat & $0.277^{* *}$ & 3.378 & $0.248^{* *}$ & 3.193 \\
\hline $\mathrm{H} 2 \mathrm{~d}$ & SocioEA -> PSocEnv & $0.357^{* * *}$ & 4.072 & $0.332^{* * *}$ & 3.648 \\
\hline $\mathrm{H} 2 \mathrm{e}$ & SocioEA -> SComm & $0.269^{*}$ & 2.624 & $0.249^{* *}$ & 3.498 \\
\hline $\mathrm{H} 3 \mathrm{a}$ & WExp -> TaskRA & 0.016 & 0.186 & 0.005 & 0.059 \\
\hline$H 3 b$ & WExp -> SocioEA & 0.128 & 1.326 & 0.131 & 1.383 \\
\hline $\mathrm{H} 4 \mathrm{a}$ & InstSup -> TaskRA & $0.273^{\star \star \star}$ & 3.558 & $0.262^{* *}$ & 3.297 \\
\hline $\mathrm{H} 4 \mathrm{~b}$ & InstSup -> SocioEA & 0.106 & 1.289 & 0.097 & 1.341 \\
\hline $\mathrm{H} 5 \mathrm{a}$ & Age $->$ TaskRA & $0.175^{\wedge}$ & 1.795 & $0.167^{\wedge}$ & 1.857 \\
\hline $\mathrm{H} 5 \mathrm{~b}$ & Age $->$ SocioEA & -0.038 & 0.371 & -0.036 & 0.397 \\
\hline $\mathrm{H} 6 \mathrm{a}$ & Gender -> TaskRA & -0.130 & 1.170 & -0.142 & 1.457 \\
\hline $\mathrm{H} 6 \mathrm{~b}$ & Gender -> SocioEA & $-0.222^{\wedge}$ & 1.998 & $-0.220^{\wedge}$ & 1.928 \\
\hline
\end{tabular}

Notes: ${ }^{* \star *}$ denotes $p<.001,{ }^{* *}, p<.01 .{ }^{*}, p<.05$ and ${ }^{\wedge} . p<.1$

\section{Table 6 - Survey 2 Results}

\begin{tabular}{|c|c|c|c|c|c|}
\hline & \multirow[t]{2}{*}{ Structural relation } & \multicolumn{2}{|c|}{ Survey 2 Model } & \multicolumn{2}{|c|}{$\begin{array}{c}\text { Controlling for Common } \\
\text { Method Bias } \\
\end{array}$} \\
\hline & & Path Coeff & t-Value & Path Coeff & t-Value \\
\hline $\mathrm{H} 1 \mathrm{a}$ & TaskRA -> AcadA & 0.133 & 1.442 & 0.038 & 0.466 \\
\hline $\mathrm{H} 1 \mathrm{~b}$ & TaskRA ->SRLearn & $0.337^{\star \star \star}$ & 3.855 & $0.445^{\star \star \star}$ & 6.239 \\
\hline $\mathrm{H} 1 \mathrm{C}$ & TaskRA -> PSat & 0.142 & 1.272 & $0.241^{*}$ & 2.557 \\
\hline $\mathrm{H} 1 \mathrm{~d}$ & TaskRA -> PSocEnv & $0.235^{*}$ & 2.595 & $0.283^{* *}$ & 3.259 \\
\hline $\mathrm{H} 1 \mathrm{e}$ & TaskRA -> SComm & 0.052 & 0.595 & 0.107 & 1.318 \\
\hline $\mathrm{H} 2 \mathrm{a}$ & SocioEA -> AcadA & $-0.196^{*}$ & 2.218 & -0.038 & 0.404 \\
\hline $\mathrm{H} 2 \mathrm{~b}$ & SocioEA -> SRLearn & $0.263^{* *}$ & 2.685 & 0.058 & 0.679 \\
\hline $\mathrm{H} 2 \mathrm{C}$ & SocioEA -> PSat & $0.318^{* *}$ & 3.069 & 0.129 & 1.224 \\
\hline $\mathrm{H} 2 \mathrm{~d}$ & SocioEA -> PSocEnv & $0.343^{* \star}$ & 3.328 & $0.309^{* *}$ & 3.282 \\
\hline $\mathrm{H} 2 \mathrm{e}$ & SocioEA -> SComm & $0.268^{* \star *}$ & 3.594 & 0.159 & 1.542 \\
\hline $\mathrm{H} 3 \mathrm{a}$ & WExp -> TaskRA & -0.094 & 1.024 & -0.111 & 1.159 \\
\hline $\mathrm{H} 3 \mathrm{~b}$ & WExp -> SocioEA & 0.020 & 0.172 & 0.085 & 0.753 \\
\hline $\mathrm{H} 4 \mathrm{a}$ & InstSup -> TaskRA & -0.043 & 0.445 & -0.066 & 0.817 \\
\hline $\mathrm{H} 4 \mathrm{~b}$ & InstSup -> SocioEA & $0.278^{*}$ & 2.478 & 0.136 & 1.320 \\
\hline $\mathrm{H} 5 \mathrm{a}$ & Age -> TaskRA & $0.150^{\wedge}$ & 1.913 & $0.134^{\wedge}$ & 1.625 \\
\hline $\mathrm{H} 5 \mathrm{~b}$ & Age -> SocioEA & 0.017 & 0.219 & -0.010 & 0.129 \\
\hline $\mathrm{H} 6 \mathrm{a}$ & Gender -> TaskRA & 0.055 & 0.555 & 0.041 & 0.437 \\
\hline $\mathrm{H} 6 \mathrm{~b}$ & Gender -> SocioEA & 0.014 & 0.160 & 0.070 & 0.782 \\
\hline
\end{tabular}

Notes: ${ }^{\star \star \star}$ denotes $p<.001,{ }^{* *}, p<.01 .{ }^{*}, p<.05$ and ${ }^{\wedge} . p<.1$ 
encouraged a conducive climate, groupthink could have occurred which prevented teams from seeing other angles and perspectives to their project (Janis 1972). This was detrimental for their project grades.

WExp did not affect TaskRA and SocioEA. Besides the earlier suggested reason, another explanation is the length of time the wiki was used and the time at which the survey was taken. Although $55.8 \%$ of the students had never used Confluence before this course, they had used the wiki for almost 4 months in the course and the survey was administered after that. Studies have shown that previous computer experience affects only the initial transfer of information (Yan 2006). Wiki experience could have given students a head start in their initial team activity but by the later stages, this initial advantage could conceivably have outlived its usefulness.

InstSup affected SocioEA but not TaskRA. The non-significant finding could be due to instructions provided by the instructor during the second semester. As aforementioned, the instructor organized a training session for the students that emphasized on wiki editing tips and possible collaboration styles on the wiki. For instance, students were informed that when deleting their team member's work, they should indicate why they deleted it. This could have resulted in students expressing politeness and courtesy on the wiki, which are forms of SocioEA. As for the lack of significance for TaskRA, it could be because the instructor did not provide other instructions about the task after the training sessions. Students were expected to complete the task by themselves.

The findings for age and gender were similar to Survey 1 . The research believes the reasons offered in the earlier discussion apply to Survey 2 too.

\section{Overall Discussion}

The findings of the two surveys reveal certain similar patterns and also some differences. The research performed a post-hoc analysis where the data was combined and the study considered as an independent variable. The post-hoc analysis found that there was no significant difference between any of the variables in the two studies. However, as the separate data analysis has shown, certain differences exist and this section attempts to integrate the results from the 2 surveys.

\section{Interaction Process and Outcomes}

In both surveys, TaskRA and SocioEA affected learning outcomes. In fact, the influence of SocioEA on learning outcomes is more significant as compared to TaskRA. For both surveys, SocioEA positively influenced 4 out of 5 learning outcomes. However, TaskRA did not consistently influence learning outcomes. TaskRA was significant for PSocEnv in both surveys only. This finding demonstrates the saliency of the effect of SocioEA on learning outcomes which has been traditionally ignored in research (Liu 2002).

TaskRA did not equally affect learning performance or socio-related outcomes in both surveys. TaskRA affected AcadA and PSat in Survey 1 but not SRLearn. In contrast TaskRA affected SRLearn but not AcadA and PSat in Survey 2. This suggests a learning/satisfaction trade-off in line with previous research (Turoff \& Hiltz 1982). Turoff and Hiltz (1982) highlight a possible compromise between team performance and satisfaction which can be mutually exclusive goals and hard to achieve simultaneously. Focusing on task-oriented activity may lead students to feel satisfied with the smooth process and produce a good project but not interrelating knowledge from the information shared. Alternatively, higher TaskRA might result in students who have gained knowledge and skills from the information exchanged but unsatisfied with their overload of information during the process which hampered the final project outcome. The different wikis utilized in the semesters could have played a part too. As mentioned, discussions in Mediawiki were more free-form and there was no specific style of discussion enforced by the software. In contrast, Confluence had a threaded discussion board at the bottom of each wiki page. This could have led students using 
Mediawiki to focus on contributing and editing content in the report without much discussion, resulting in a good quality report and satisfaction at the ease of collaboration. On the other hand, students using Confluence could have spent more time using the threaded discussion board to discuss and share their thoughts. This may have made it difficult for them to translate their discussion into the report on the wiki, resulting in less PSat and AcadA.

TaskRA did not affect SComm according to the hypothesis in both surveys. This suggests that task-related information sharing is not enough to help students to connect with each other. Survey 1 reveals that TaskRA led to less SComm suggesting that too much focus on the TaskRA prevents team members from developing common ground and instead caused them to feel more distant from each other. This is consistent with research that has found CMC harder to build social relations (Liu 2002); deliberate effort has to be taken i.e. increasing SocioEA, to increase SComm.

On the other hand, SocioEA affected both learning performance and socio-related outcomes rather similarly. The influence of SocioEA was consistent in both surveys. Results from both surveys showed SocioEA significantly influencing SRLearn, PSat, PSocEnv and SComm. However, SocioEA did not have such a positive impact on AcadA. While there was no effect of SocioEA on AcadA in Survey 1 , this was significant in the negative direction in Survey 2. In the earlier discussion, reasons such as students' oriented towards group agreement and group think were suggested. Group think has led to several unfavorable performances in group decision-making (Janis 1972). Another reason could be that SocioEA was measured to be positive in nature and did not take into account conflicts in the team. Research has shown that some degree of conflict is necessary for quality work to be produced. Through the argumentation and negotiation of ideas, better solutions are derived (Vygotsky 1978).

\section{Inputs}

For WExp, both surveys showed no relationship between experience and TaskRA and SocioEA. It seems that for both types of wiki software, experience does not matter in influencing the level of activity. Students with less WExp are able to interact equally as well as students with more WExp after some time of usage. Usage familiarity can be built up relatively quickly such as in the 4 months that students' used the wiki in this study.

The results of the role of the instructor were rather different in the two surveys. This can be attributed to the slightly different ways the instructor conducted the course in the two semesters and also how the wiki was set-up. In the first semester, the instructor focused only on providing instructions on the task and technical help with using the wiki. This could have led students to produce more taskoriented information and little SocioEA. In the second semester, in addition to project details and technical help, the instructor emphasized on collaboration tips and ways to manage group dynamics. This could have led students to produce more SocioEA rather than TaskRA. Another possible explanation was the way the wiki was set-up. Mediawiki was set-up by a tutor specifically for the course. Students (including other students not in the same team) and staff in the course could view the various reports on the wiki. Students could have concentrated on producing the best report as they knew other teams could read their report, leading to greater information exchange about the task. On the other hand, Confluence was set-up by the University and all university students had access to it. However, Confluence allowed teams to setup their page with a private level of visibility. Other students could not view their work, which provided students with more privacy. This could have resulted in more open sharing of feelings and intimate details i.e. higher SocioEA.

The results for age were similar across both surveys. Age affected TaskRA but not SocioEA. Older learners produced higher TaskRA 
probably as a result of their deep learning strategy which necessities more discussion and negotiation. On the other hand, learners from all ages were able to generate similar levels of SocioEA. A possible reason is that while older learners had the experience and maturity for group maintenance behaviors, younger learners were more comfortable with expressing SocioEA in the online medium. This resulted in similar levels of SocioEA for learners of different ages.

As for gender, the results of both surveys suggest that gender interaction processes are more complex than initially hypothesized. Although gender stereotypes exist, individuals adjust to the gender composition of the team they are in, and interact in ways that differ from their gender stereotype (Savicki \& Kelley 2000). As previously discussed, females in mixed-gender teams tend to act more taskoriented and less socio-emotional-oriented, almost akin to traditional male behavior. Some research has explained that this is a coping mechanism adopted by females due to the perception of having lower status or the weaker sex (Flanagin et al. 2002). This could account for the unsupported hypotheses for the relationship between gender and TaskRA and SocioEA.

\section{Implications}

The results of the study provide practical and research implications. The research first examines the two different wiki software. Both surveys reveal that the learning outcomes from the two wikis were more similar than different. The one exception was that TaskRA in Mediawiki led to higher AcadA and PSat but not SRLearn; this finding was reverse in Confluence. As earlier explained this could be because of the threaded discussion forum feature in Confluence which was not available in Mediawiki, and Mediawiki's focus on displaying the content of the report. This implies that wikis may not contain all the features necessary to facilitate all learning outcomes. Further improvement with wiki software to support collaborative learning is necessary. To help in further research and practice on wiki effectiveness, the paper has developed a classification system of wikis based on the current findings, extant literature and observations of the wiki marketplace.

Mediawiki and Confluence are different wiki software. Yet when the two software was used for the same project, the empirical results were strikingly similar. The data revealed similar learning outcomes from positive SocioEA in both wikis. Indeed, the essence of these two wiki software is that they are browser-based workspaces that allow collaborators to edit and track changes. This suggests that both Mediawiki and Confluence can be seen as similar systems. They are also similar to other wikis in the marketplace with these basic sets of features such as PBWorks and TikiWiki.

The classification of systems is also based on the framework of three levels of systems for group decision support systems (GDSSs) developed by DeSanctis and Gallupe (1987). This research first proposed that Level 1 GDSSs provide basic communication between members while Level 2 GDSSs are enhanced from Level 1 to provide modeling techniques to reduce the uncertainty in decisions. Level 3 GDSSs are the most sophisticated and make use of automated rules and artificial intelligence (DeSanctis \& Gallupe 1987; Colton \& Bower 2002).

Adapting the conceptual framework of system levels, the paper develops a framework for wiki group work consisting of 3 levels of systems. Level 1 wiki systems are wiki software that encompasses the basic features of wikis. These basic features include the shared editing functions, tracking functions and page permissions present in any wiki. Moreover, these features are also asynchronous in nature; they facilitate information exchange of users at their own time and place.

Level 2 systems are wiki software that is substantially enhanced. The enhancements can include features such as group chats to allow more spontaneous communication between members or drawing boards for users to sketch. Level 3 systems are wiki software that is integrated with other organizational wide systems providing a suite of applications 


\begin{tabular}{|c|l|l|}
\hline $\begin{array}{c}\text { Table } 7 \text { - Three levels of systems for wiki group work } \\
\text { Wiki }\end{array}$ & \multicolumn{1}{|c|}{ Definition } \\
\hline $\begin{array}{c}\text { Level } \\
\text { One }\end{array}$ & $\begin{array}{l}\text { The essential features of a wiki including } \\
\text { shared editing, tracking functions and } \\
\text { page permissions. }\end{array}$ & $\begin{array}{l}\text { Easic versions of Mediawiki, Confluence, Wetpaint, } \\
\text { PmWiki, Google Sites etc. }\end{array}$ \\
\hline $\begin{array}{c}\text { Level } \\
\text { Two }\end{array}$ & $\begin{array}{l}\text { Wiki software that are substantially en- } \\
\text { hanced typically by plug-ins or macros. } \\
\text { These enhancements augment the } \\
\text { basic features of a wiki. For example, } \\
\text { group chats and drawing boards. }\end{array}$ & $\begin{array}{l}\text { Mediawiki: Rating and review extension, Google- } \\
\text { Confluence: Google calendar embed, Gliffy plug-in } \\
\text { for flowcharts, and MeetingRoom macro for group } \\
\text { chats etc. }\end{array}$ \\
\hline $\begin{array}{l}\text { Level } \\
\text { Three }\end{array}$ & $\begin{array}{l}\text { Wiki software that are integrated with } \\
\text { other organizational wide systems } \\
\text { providing a suite of applications where } \\
\text { data from one application can be easily } \\
\text { transported to another application. }\end{array}$ & $\begin{array}{l}\text { Confluence: integration with Microsoft SharePoint, } \\
\text { Salesforce.com, and IBM's Lotus Connections etc. } \\
\text { Google Sites: integration with the rest of Google } \\
\text { Apps such as Gmail, Google Groups, and Google } \\
\text { Docs. }\end{array}$ \\
\hline
\end{tabular}

where data from one application can be easily transported to another application.

These 3 levels of systems are currently being seen in the IT marketplace. The basic Confluence wiki is a Level 1 wiki system with the central features of a wiki. This was the system level examined in the current study. However, Confluence has macros and plugins to enhance it to a Level 2 wiki. Examples of such plug-ins include a Google calendar embed, Gliffy plug-in to create flowcharts, and a MeetingRoom macro for group chats. Level 3 wiki systems are also possible with Confluence which allows full integration with Microsoft SharePoint, Salesforce.com, and IBM's Lotus Connections etc. Table 7 illustrates the 3 levels of systems for wiki group work.

For system designers of wikis, the conceptual framework illustrating the three levels of systems serves as a way of classifying the features of the wiki. Wikis can be enhanced with features that provide ease of collaboration and collaborative learning. From this study, it seems that allowing more avenues for students to communicate on Mediawiki could enhance the SRLearn of students. Future developers could implement the Mediawiki with a threaded discussion forum or even a group chat, which can be implemented through installing a plug-in. On the other hand, it seems that more focus on the content is required in
Confluence, and the developers could develop other enhancements to help transfer discussions from the discussion space to the content space. All these added features in the wiki system would enhance the wiki such that it would be classified as a level two system.

This is also a way for developers of existing level one systems to expand their offerings such that levels two and three wiki systems can be catered for. This could in turn affect their wiki adoption rates and reputation. For instance, for Mediawiki, there is currently no level three system which provides integration to application suites. Mediawiki developers can provide integration to other open source organizational suites such as OpenOffice which can potentially lead to greater interaction and outcomes for group members.

Moreover, the current study has shown that SocioEA affect outcomes. While not ignoring the instrumental needs in team projects, designers should also cater for SocioEA by developing functions that will maintain the positive activity of the team. For instance, a positivity level indicator plug-in could be added to wiki systems.

This framework also serves as a guide for educators in selecting wiki software. As a baseline, level one systems provide the basic features for collaboration and outcomes. As shown in the study, using wikis for team projects does affect learning performance and 
socio-related outcomes. However, not all learning outcomes seem to be catered for in every wiki software. Educators may need to choose a level 2 wiki system which can possibly enhance more learning outcomes.

Another practical takeaway for educators is with regard to the inputs, WExp, InstSup, and age. The study's findings suggest that WExp should not be too much of an issue for educators in deciding to adopt a wiki for collaborative learning. WExp did not affect interaction processes or learning outcomes. Rather, educators should select a wiki software that fits their personal and/or organizational goals. As for InstSup, this is crucial in enhancing TaskRA and SocioEA. Educators should provide equal emphasis on instruction with regard to the project at hand as well as the group maintenance functions. This will encourage students to contribute both TaskRA and SocioEA. Lastly, the findings suggest that younger learners may not be able to share as much TaskRA as compared to older learners. Educators should encourage these younger learners to be critical of information collated and discuss them in greater detail rather than gloss over them superficially.

Next, the paper suggests area for future research. First, the paper has examined level one wiki systems and shown how they have affected learning outcomes. Further research could investigate level two and level three systems to verify their effectiveness. A possible future study can compare between level one and level two wiki systems and determine the extent of effectiveness for team projects.

Second, gender composition in team projects using wikis could be further examined. The findings from this study indicate that the gender composition in teams affected the interaction behavior and outcomes. Team composition in future studies could be specifically manipulated such as forming mixed-gender, all female and all male teams and its impact investigated.

Third, the study highlights the pitfall of only focusing on TaskRA. Further studies should continue to examine SocioEA in addition to
TaskRA. This will extend the line of study by Bales (1950) for a relatively new type of IT, the wiki. One particular area could be the degree to which the two activities are needed for learning outcomes i.e. the balance of the two communication activities. Another area is to examine the temporal nature of the two activities, where a particular activity could be crucial at a certain phase or stage in a group's lifespan.

Fourth, to further evaluate the effectiveness of wikis, other studies should compare between traditional face-to-face teams and teams using wikis. This can provide further evidence of the effectiveness of wikis.

\section{Conclusion}

This paper examines the learning outcomes of wikis for team projects using the functional perspective. Specifically, the paper has found that wikis can affect learning outcomes of AcadA, SRLearn, PSat, PSocEnv and SComm through the processes of TaskRA and SocioEA. While WExp did not affect interaction activity, InstSup was able to influence both activities. Age also affected TaskRA but not SocioEA while the effect of gender highlights the importance of group composition.

Among its contributions, this paper is one of the few empirical studies that rigorously examine the use of wikis and learning outcomes. Moreover, the relationship is robust enough to be observed in two separate wikis which possessed different features.

The research has also delineated the importance of examining both instrumental and expressive needs of teams. Previous studies have tended to focus on task-oriented activity, suggesting that collaboration systems only cater for that. However, this paper has shown that TaskRA and SocioEA both affect learning outcomes. Moreover, the data shows stronger support for the relationship between positive SocioEA and learning outcomes as compared to TaskRA. This highlights the importance of examining SocioEA in group work.

Furthermore, the study has provided practical and theoretical suggestions for educators, 
system developers and researchers. This includes the three levels of systems for wiki group work which can be used as a guide for practice and future research.

Despite these contributions, the study suffers from several limitations. The research did not design a comparison between two wiki software, or wiki software and other types of collaboration software or with face-to-face collaboration. This limits the extent to which the claim of wiki effectiveness can be drawn. Based on the study, the research provides evidence that using wikis for team projects enhance learning outcomes for learners.

Another limitation is that the researchers were unable to guarantee that all the features of the wiki were utilized. For instance students might not have uploaded a photo or used the discussion pages in the wiki. Nevertheless, as the paper conceptualized, these two wikis can be considered to be at the same level i.e. level 1 wiki systems, which contain basic wiki features. Based on similar findings from both surveys, the paper suggests that these two wikis are roughly equivalent.

Next, the paper uses the survey methodology which limits the identification of causation. The survey also had small sample sizes and not all students who used the wiki participated in the survey. Nevertheless, the causeeffect linkages were theoretically sound and the survey was replicated twice resulting in similar findings, suggesting the soundness of the model.

In addition, the results from this study may not be able to generalize to other contexts due to the uniqueness of the team, task etc. Collaborative learning and virtual team constructs were also not examined. Going further, the research agenda will be to examine other factors such as wiki system levels to develop a more comprehensive study of wiki effectiveness.

In sum, the paper has contributed a greater insight of wiki effectiveness together with a rigorous empirical study conducted using two wikis. It has illuminated the black-box of in- put-output models by examining both task and social aspects of team interaction activity and the impact of wiki experience, instructor support, age and gender on TaskRA and SocioEA. This adds to the body of literature examined through the lens of the functional perspective. Moreover, the data strongly supports that interaction processes affect learning outcomes. In particular, positive SocioEA enhances SRLearn, PSat, PSocEnv and SComm. Additionally, a framework of wiki system levels is conceptualized that provides direction for future research and practice.

Wikis are being rampantly used in many industries. This is no different in education. This paper provides a theoretical lens for the effectiveness of wikis for student team projects. Tested using two separate wikis (Mediawiki and Confluence) over a protracted period of one semester, findings show consistent and strong support for wiki effectiveness. Indeed, this line of research coupled with popular support for the wiki points to a bright future for wiki use and evolution.

\section{Footnotes}

\footnotetext{
WYSIWYG editing refers to software where "what you see is what you get" i.e. users' typed messages are equivalent to what they see on the screen. Software that does not have WYSIWYG editing requires the entering of mark-up language which is different from what will finally be displayed.

2 Instruction: Please think about the process of how you completed your project. To what extent were the following displayed?
}

\section{References}

Alavi, M. (1994). Computer-mediated collaborative learning: an empirical evaluation. MIS Quarterly, 18(2), 59-174.

Arbaugh, J., and Benbunan-Fich, R. (2006). An investigation of epistemological and social dimensions of teaching in online learning environments. Academy of Management Learning Education, 5(4), 435-447.

Bales, R. (1950). A set of categories for the analysis of small group interaction. Annual Sociology Review, 15(2), 257263. 
Barab, S., and Duffy, T. (2000). From practice fields to communities of practice. Theoretical foundations of learning environments (pp. 25-56). Mahwah, $\mathrm{NJ}$ : Lawrence Erlbaum.

Benbunan-Fich, R., Hiltz, S., and Turoff, M. (2003). A comparative content analysis of face-to-face vs. asynchronous group decision making. Decision Support Systems, 34(4), 457-469.

Bloom, B. (1956). Taxonomy of educational objectives, Handbook I: the cognitive domain. New York: David McKay Co.

Bonk, C., Malinowski, S., Angeli, C., and East, J. (1998). Web-based case conferencing for pre-service teacher education: electronic discourse from the field. Journal of Educational Computing Research, 19(3), 269-306.

Carr, T., Morrison, A., Cox, G., and Deacon, A. (2007). Weathering wikis: netbased learning meets political science in a south african university. Computers and Composition, 24(3), 266-284.

Chen, H., Cannon, D., Gabrio, J., Leifer, L., Toye, G., and Bailey, T., et al. (2005). Using wikis and weblogs to support reflective learning in an introductory engineering design course. In Proceedings of the American Society for Engineering Education Annual Conference \& Exposition.

Chin, W. (1998). The partial least squares approach for structural equation modeling. Modern Methods for Business Research (pp. 295-336). Hillsdale, NJ: Erlbaum.

Chou, S. W., and Min, H. T. (2009). The impact of media on collaborative learning in virtual settings: the perspective of social construction. Computers \& Education, 52, 417-431.

Chudoba, K. M., Wynn, E., Lu, M., and Watson-Manheim, M. B. (2005). How virtual are we? measuring virtuality and understanding its impact in a global organization. Information Systems Journal, 15(4), 279-306.

Colton, J. A., and Bower, K. M. (2002). Some misconceptions about $\mathrm{r}^{2}$. EXTRAOrdinary Sense, 3(2), 20-22.

Cress, C., and Kimmerle, J. (2008). A systemic and cognitive view on collaborative knowledge building with wikis. International Journal of ComputerSupported Collaborative Learning, 3(2), 105-122.

Cubric, M. (2007). Wiki-based process framework for blended learning. In Proceedings of the International Symposium on Wikis (pp. 11-24). Montreal, Quebec, Canada. New York: ACM.

De Laat, M., Lally, V., Lipponen, L., and Simons, R. J. (2007). Online teaching in networked learning communities: approach to studying the role of the teacher. Instructional Science, 35(2007), 257-286.

DeSanctis, G., and Gallupe, R. B. (1987). A foundation for the study of group decision support systems. Management Science, 33(5), 589-609.

Dille, B., and Mezack, M. (1991). Identifying predictors of high risk among community college telecourse students. The American Journal of Distance Education, 5(1), 24-35.

Ebersbach, A., Glaser, M., Heigl, R., and Warta, A. (2008). Wiki: web collaboration. (2 ed.). Berlin Heidelberg: Springer-Verlag.

Elgort, I. (2008). Using wikis as a learning tool in higher education. In Proceedings of the ascilite, Singapore.

Flammia, M., Cleary, Y., and Slattery, D. (2010). Leadership roles, socioemotional communication strategies, and technology use of irish and us students in virtual teams. IEEE Transactions on Professional Communication, (2), 89-101. 
Flanagin, A. J., Tiyaamornwong, V., O'Connor, J., and Seibold, D. R. (2002). Computer-mediated group work: the interaction of sex and anonymity. Communication Research, 29(1), 6693.

Fornell, C. (1982). Second generation of multivariate analysis methods. New York: Praeger.

Forte, A., and Bruckman, A. (2007). Constructing text: wiki as a toolkit for (collaborative?) learning. In Proceedings of the International Symposium on Wikis (pp. 31-42). Montreal, Quebec, Canada. New York: ACM Press.

Fuchs-Kittowski, F., and Köhler, A. (2005). Wiki communities in the context of work processes. In Proceedings of the International Symposium on Wikis (pp. 33-39). New York: ACM Press.

Fuller, M. A., Hardin, A. M., and Davison, R. M. (2006). Efficacy in technologymediated distributed teams. Journal of Management Information Systems, 23(3), 209-235.

Garrison, D. R., Anderson, T., and Archer, W. (2000). Critical inquiry in a text-based environment: computer conferencing in higher education. The Internet and Higher Education, 2(2-3), 87-105.

Gow, L., and Kember, D. (1990). Does higher education promote independent learning? Higher Education, 19(3), 307-322.

Green, S., and Taber, T. (1980). The effects of three social decision schemes on decision group process. Organizational Behavior and Human Performance, 25(1), 97-106.

Guiller, J., and Durndell, A. (2007). Students' linguistic behaviour in online discussion groups: does gender matter? Computers in Human Behavior, 23(5), 2240-2255.

Guzdial, M., Rick, J., and Kehoe, C. (2001). Beyond adoption to invention: teacher-created collaborative activities in higher education. The Journal of the Learning Sciences, 10(3), 265-279.

Hahn, S., and Litwin, A. (1995). Women and men: understanding and respecting gender differences in the workplace. Managing in the Age of Change - Essential Skills to Manage Today's Diverse Workforce (pp. 188-198). New York: Irwin.

Harter, S. (1999). The construction of the self: a developmental perspective. New York: Guilford Press.

Hew, K., and Cheung, W. (2009). Use of wikis in k-12 and higher education: a review of the research. International Journal of Continuing Engineering Education and LifeLong Learning, 19(2/3), 141-165.

Hills, P., and Argyle, M. (2003). Uses of the internet and their relationships with individual differences in personality. Computers in Human Behavior, 19(1), 59-70.

Hong, K. S. (2002). Relationships between students' and instructional variables with satisfaction and learning from a web-based course. The Internet and Higher Education, 5(3), 267-281.

Hoyle, R. H., and Crawford, A. M. (1994). Use of individual-level data to investigate group phenomena issues and strategies. Small Group Research, 25(4), 464-485.

Janis, I. L. (1972). Victims of groupthink. New York: Houghton Mifflin.

Jarvenpaa, S. L., Shaw, T. R., and Staples, D. S. (2004). Toward contextualized theories of trust: the role of trust in global virtual teams. Information Systems Research, 15(3), 250-267.

Kane, G. C., and Fichman, R. G. (2009). The shoemaker's children: using wikis for information systems teaching, research, and publication. MIS Quarterly, 33(1), 1-17. 
Assessing IT-business alignment in service-oriented enterprises / Koh \& Lim

Kanuka, H., Rourke, L., and Laflamme, E. (2007). The influence of instructional methods on the quality of online discussion. British Journal of Educational Technology, 38(2), 260-271.

Karuppan, C. M. (2001). Web-based teaching materials: a user's profile. Internet Research, 11(2), 138-148.

Kray, L. J., Galinsky, A. D., and Thompson, L. (2002). Reversing the gender gap in negotiations: an exploration of stereotype regeneration. Organizational Behavior and Human Decision Processes, 87(2), 386-410.

Kreijns, K., Kirschner, P., and Jochems, W. (2002). The sociability of computersupported collaborative learning environments. Journal of Education Technology \& Society, 5(1), 8-22.

Kreijns, K., Kirschner, P., Jochems, W., and van Buuren, H. (2007). Measuring perceived sociability of computersupported collaborative learning environments. Computers \& Education, 49(2), 176-192.

Leuf, B., and Cunningham, W. (2001). The wiki way: quick collaboration on the web. Boston: Addison Wesley.

Liang, H., Saraf, N., Hu, Q., and Xue, Y. (2007). Assimilation of enterprise systems: the effect of institutional pressures and the mediating role of top management. MIS Quarterly, 31(1), 59-87.

Lind, M. (1999). The gender impact of temporary virtual work groups. IEEE Transactions on Professional Communication, 42(4), 276-285.

Liu, Y. (2002). What does research say about the nature of computer-mediated communication: task-oriented, socialemotion-oriented, or both? Electronic Journal of Sociology, 6(1). Retrieved Aug 10, 2009, from http://www.sociology.org/content/vol0 06.001/liu.html
Lou, Y., Abrami, P., and d'Apollonia, S. (2001). Small group and individual learning with technology: a metaanalysis. Review of Educational Research, 71(3), 449-521.

Lund, A., and Smødal, O. (2006). Is there a space for the teacher in a wiki? In Proceedings of the International Symposium on Wikis (pp. 37-46). New York: ACM Press.

Mader, S. (2006). Using wiki in education. Retrieved May 4, 2009, from http://www.wikiineducation.com

McAfee, A. (2006). Enterprise 2.0: the dawn of emergent collaboration. MIT Sloan Management Review, 47(3), 21-28.

McGrath, J. (1991). Time, interaction, and performance (tip): a theory of groups. Small Group Research, 22(2), 147174.

Mindel, J., and Verma, S. (2006). Wikis for teaching and learning. Communications of the Association for Information Systems, 18(2006), 1-23.

Minocha, S., and Thomas, P. (2007). Collaborative learning in a wiki environment: experiences from a software engineering course. New Review of Hypermedia and Multimedia, 13(2), 187209.

Nicol, D., Littlejohn, A., and Grierson, $\mathrm{H}$. (2005). The importance of structuring information and resources within shared workspaces during collaborative design learning. Open Learning, 20(1), 31-49.

Nunnally, J. (1978). Psychometric theory. (2 ed.). New York: McGraw-Hill.

Parker, K. R., and Chao, J. T. (2007). Wiki as a teaching tool. Interdisciplinary Journal of Knowledge and Learning Objects, 358-72.

Podsakoff, P. M. 1., MacKenzie, S. B., Lee, J. Y., and Podsakoff, N. P. (2003). Common method biases in behavioral research: a critical review of the litera- 
ture and recommended remedies. Journal of Applied Psychology, 88(5), 879-903.

Ramanau, R., and Geng, F. (2009). Researching the use of wiki's to facilitate group work. Procedia Social and Behavioral Sciences, 12, 620-2626.

Ras, E., Carbon, R., Decker, B., and Rech, J. (2007). Experience management wikis for reflective practice in software capstone projects. IEEE Transactions on Education, 50(4), 312-320.

Ravid, G., Kalman, Y. M., and Rafaeli, S. (2008). Wikibooks in higher education: empowerment through online distributed collaboration. Computers in Human Behavior, 24(2008), 1913-1928.

Richardson, J. T. E. (1994). Mature students in higher education: i. a literature survey on approaches to studying. Studies in Higher Education, 19(3), 309325.

Rick, J., and Guzdial, M. (2006). Situating coweb: a scholarship of application. International Journal of ComputerSupported Collaborative Learning, 1(1), 89-115.

Robey, D., Khoo, H. M., and Powers, C. (2000). Situated learning in crossfunctional virtual teams. IEEE Transactions on Professional Communication, 47(1), 51-66.

Rovai, A. (2002). Development of an instrument to measure classroom community. Internet and Higher Education, 5(3), 197-211.

Savicki, V., and Kelley, M. (2000). Computer mediated communication: gender and group composition. CyberPsychology \& Behavior, 3(5), 817-826.

Schacht, P. (2006). The collaborative writing project. In S. Mader (Ed.), Using Wiki in Education (pp.12-23). Retrieved May 4, 2009, from http://www.wikiineducation.com
Shih, P. C., Muñoz, D., and Sánchez, F. (2006). The effect of previous experience with information and communication technologies on performance in a web-based learning program. Computers in Human Behavior, 22(6), 962970.

Swan, S., Shea, P., Fredericksen, E., Pickett, A., Pelz, W., and Maher, G., et al. (2000). Building knowledge building communities: consistency, contact and communication in the virtual classroom. Journal of Educational Computing Research, 23(4), 359-383.

Tamhane, A., and Dunlop, D. (2000). Statistics and data analysis: from elementary to intermediate. Upper Saddle River, NJ: Prentice Hall.

Thomson, R. (2006). The effect of topic of dicussion on gendered language in computer-mediated discussion. Journal of Language and Social Psychology, 25(2), 167-178.

Turoff, M., and Hiltz, S. (1982). Computer support for group versus individual decisions. IEEE Transactions on Communications, 30(1), 82-91.

Tutty, J. I., and Klein, J. D. (2008). Computermediated instruction: a comparison of online and face-to-face collaboration. Educational Technology Research and Development, 56(2), 101-124.

Vygotsky, L. (1978). Mind in society. Cambridge, MA.: Harvard University Press.

Wagner, C. (2004). Wiki: for conversational knowledge management and group collaboration. Communications of the Association for Information Systems, 13(2004), 265-289.

Whitworth, B., Gallupe, B., and McQueen, R. (2000). A cognitive three-process model of computer-mediated group interaction. Group Decision and Negotiation, 9(5), 431-456.

Wildt, A. R. (1976). On evaluating market segmentation studies and the proper- 
Assessing IT-business alignment in service-oriented enterprises / Koh \& Lim

ties of $r^{2}$. Management Science, 22(8), 904-908.

Wittenbaum, G. M., Hollingshead, A. B., Paulus, P. B., Hirokawa, R. Y., Ancona, D. G., and Peterson, R. S., et al. (2004). The functional perspective as a lens for understanding groups. Small Group Research, 35(1), 17-43.

\section{About Authors}

Elizabeth Koh is a doctoral candidate and instructor at the Department of Information Systems, in the School of Computing, National University of Singapore. Her research interests include IT and education, virtual teams, and social computing. Her work has been published in several journals and conferences including the Information Resources Management Journal, the International Conference on Human-Computer Interaction, and the Pacific-Asia Conference on Information Systems.
Yan, Z. (2006). Different experiences, different effects: a longitudinal study of learning a computer program in a network environment. Computers in Human Behavior, 22(3), 364380.

Dr. John Lim is Associate Professor in the School of Computing, Department of Information Systems, at the National University of Singapore. His research interests include IT and education, collaborative technology, negotiation support, and media effects. He has published in journals such as the Journal of Management Information Systems, Decision Support Systems, Small Group Research and International Journal of Web-based Learning and Teaching Technologies. 